\title{
O TRABALHO INFANTIL NO BRASIL COMO SUBTRAÇÃO DE DIREITOS HUMANOS E SUA RELAÇÃO COM O LABOR FORÇADO
}

\author{
Germano Schwartz ${ }^{1}$ \\ Gabriela Di Pasqua ${ }^{2}$
}

\begin{abstract}
RESUMO: Este artigo estuda o trabalho infantil no Brasil enquanto fenômeno violador de direitos humanos e sua relação com o labor forçado. Na primeira etapa de pesquisa, verificase o trabalho infantil a partir do cenário brasileiro; já na segunda etapa de estudo, analisa-se os principais dados do trabalho infantil no Brasil, disponibilizados pelas instituições e organizações temáticas, por meio das lentes de uma outra violação de direitos humanos que muito se assemelha ao trabalho infantil: o trabalho escravo. Na terceira parte do trabalho, com o fito de finalização da pesquisa, aborda-se as principais ações de combate ao trabalho infantil no Brasil.
\end{abstract}

PALAVRAS-CHAVES: Trabalho Infantil; Direitos Humanos; Direitos Fundamentais; Trabalho Escravo Contemporâneo; Direitos da Criança e do Adolescente.

\section{CHILD LABOR IN BRAZIL AS SUBTRACTION OF HUMAN RIGHTS AND ITS RELATIONSHIP WITH FORCED LABOR}

\begin{abstract}
This article studies child labor in Brazil as a phenomenon that violates human rights and its relationship with forced labor. In the first stage of research, child labor is verified from the Brazilian scenario; in the second stage of study, the main data on child labor in Brazil, made available by institutions and thematic organizations, is analyzed through the lens of another human rights violation that is very similar to child labor: slave labor. In the third part of the work, with the aim of finalizing the research, the main actions to combat child labor in Brazil are addressed.
\end{abstract}

KEYWORDS: Child Labor; Human Rights; Fundamental Rights; Contemporary Slave Labor; Child and Teenagers Rights.

\section{INTRODUÇÃO}

Eu tinha 14 anos... foi em 2015 . Eu trabalhava em uma casa de salgados, eu ia lavar
uma louça, empanar uns salgados e esse tipo de coisa. Aí num dia a dona do
estabelecimento me botou numa máquina e foi onde eu sofri meu acidente. O
"socador" não era daquela máquina, era de uma outra máquina, e não era suficiente
para desentupir, aí eu fui desentupir e botei a mão. Só que como ela é elétrica, eu

\footnotetext{
${ }^{1}$ Reitor do Centro Universitário Ritter dos Reis (UniRitter), da FADERGS e do IBMR. Doutor em Direito (UNISINOS) com estágio-sanduíche na Universidade de Paris X-Nanterre. Estágio pós-doutoral na University of Reading. Bolsista de Produtividade em Pesquisa CNPq (Nível 2). Pesquisador Gaúcho (FAPERGS).

${ }^{2}$ Mestranda em Direitos Humanos pela UniRitter, com bolsa da CAPES (Processo $\mathrm{n}^{\circ}$ 88882.367100/2019-01). Graduada em Direito pela UniRitter. Assessora de Promotor de Justiça do Ministério Público do Rio Grande do Sul, com atuação na matéria atinente à infância e juventude.
} 
não consegui desligar, aí puxou minha mão... direto, em questão de segundos, muito rápido. Aí eu fiquei presa por quarenta minutos porque eu não conseguia tirar meu braço, e demorou um pouco para os bombeiros e a ambulância virem."

"Não tem mais o que se fazer, mãe. Ela moeu toda a mãozinha. A única coisa que tem a fazer é amputar... foi isso (choro). (MPT, Documentário "Ser Criança," 2018). [transcrição dos autores].

O trecho em epígrafe fora extraído do depoimento de uma adolescente e sua mãe, residentes na cidade de Canoas, no Rio Grande do Sul/Brasil, relatando o acidente de trabalho que ocasionou na amputação de um dos braços da menina. Ela tinha quinze anos.

Diante do lastimável relato, apresenta-se a temática da presente pesquisa: trabalho infantil no Brasil.

Nada obstante ao fato do problema ter sofrido significativa redução desde a década de 90 , vislumbrada principalmente pós-Constituição Federal de 1988, o trabalho infantil é uma realidade no Brasil, ao passo que os indicadores oficiais apontam um número que ultrapassa os 2 milhões de crianças e adolescentes em situação de trabalho precoce no território brasileiro.

Nesse ínterim, considerando esse cenário, tem-se o seguinte problema de pesquisa (aqui apresentado em forma de questionamento): em que medida o trabalho infantil brasileiro se configura como fenômeno violador de Direitos Humanos e qual sua relação com o trabalho escravo?

Assim, este artigo justifica-se por se tratar o trabalho infantil de um instrumento totalmente atentatório aos Direitos Humanos e Fundamentais das crianças e adolescentes, se tendo um expressivo número de infantes em situação de labor precoce no Brasil e no mundo.

Para tanto, o estudo desenvolve-se em três partes: na primeira etapa de pesquisa, constroise um panorama geral sobre o trabalho infantil, enquanto fenômeno violador de Direitos Humanos e Fundamentais, a partir do cenário brasileiro; em segundo, analisa-se os principais dados do trabalho infantil no Brasil, disponibilizados pelas instituições e organizações temáticas, por meio das lentes de uma outra violação humanitária, a qual em muito se assemelha ao trabalho infantil: o trabalho escravo. Na terceira e última parte do trabalho, aborda-se as principais ações de combate ao trabalho infantil no Brasil.

A metodologia de pesquisa é exploratória-bibliográfica, constituindo-se em análise da doutrina, diplomas legais, bem como coletas de dados nas plataformas digitais das instituições 
e organizações atuantes na temática do trabalho infantil. O método é o dedutivo, pois buscase, a partir de premissas gerais, alcançar premissas específicas.

\section{O TRABALHO INFANTIL COMO SUBTRAÇÃO DE DIREITOS HUMANOS: ESPECTRO DO CENÁRIO BRASILEIRO}

A Organização Internacional do Trabalho (OIT) estimou que, em 2016, no mundo, existiam 152 milhões de crianças, entre os 5 e 17 anos de idade, em situação de trabalho infantil. Esse número é expressado por 88 (oitenta e oito) milhões de meninos, enquanto 64 (sessenta e quatro) milhões forma-se por meninas. ${ }^{3}$

O ranking é liderado pelo continente africano, o qual abriga 72 milhões de crianças trabalhando, seguido da região Ásia-Pacífico, com 62 milhões, das Américas, que contam 10.7 milhões, da Europa e da Ásia Central com 5.5 milhões, culminando com 1.2 milhão de crianças em condição de trabalho infantil no mundo árabe. Os dados também são apontados pela OIT, em índice formulado no ano de $2016 .^{4}$

No Brasil, aponta-se o número de 2.7 milhões de crianças e adolescentes em situação de trabalho infantil, dado esse indicado pela OIT, em reiteração ao estudo feito pela Pesquisa Nacional por Amostra de Domicílios (PNAD/IBGE), no ano de $2015 .^{5}$

Em termos de proteção jurídico-constitucional, preceitua o artigo 227, caput, da Constituição Federal (CF), que é dever da família, da sociedade e do Estado assegurar todos os direitos e garantias constitucionais da criança e do adolescente para sua plena evolução como ser humano em todas as esferas da vida. ${ }^{6} \mathrm{O}$ aludido dispositivo constitucional consolida

\footnotetext{
${ }^{3}$ ORGANIZAÇÃO INTERNACIONAL DO TRABALHO. Estimativas globais de trabalho infantil: resultados e tendências 2012-2016. International Labour Office (ILO), Geneva, 2017. 19 set. 2017. Disponível em: <https://www.ilo.org/wcmsp5/groups/public/---dgreports/---dcomm/documents/publication/wcms_575499.pdf>. Acesso em 30 mar. 2020.

${ }^{4}$ ORGANIZAÇÃO INTERNACIONAL DO TRABALHO. Trabalho Infantil. OIT Brasília. 19 set. 2017. Disponível em: <https://www.ilo.org/brasilia/temas/trabalho-infantil/lang--pt/index.htm>. Acesso em $30 \mathrm{mar}$. 2020.

${ }^{5}$ Tal dado e outros relacionados ao trabalho infantil podem ser encontrados por meio do seguinte endereço eletrônico: <https://www.ilo.org/brasilia/temas/trabalho-infantil/lang--pt/index.htm>. Acesso em 30 mar. 2020.

${ }^{6}$ Art. 227. É dever da família, da sociedade e do Estado assegurar à criança, ao adolescente e ao jovem, com absoluta prioridade, o direito à vida, à saúde, à alimentação, à educação, ao lazer, à profissionalização, à cultura, à dignidade, ao respeito, à liberdade e à convivência familiar e comunitária, além de colocá-los a salvo de toda forma de negligência, discriminação, exploração, violência, crueldade e opressão.
} 
o chamado sistema especial de proteção dos direitos fundamentais das crianças e dos adolescentes, advindos da sua peculiar condição de pessoa em desenvolvimento ${ }^{7}$ (MACHADO, 2003, p. 105).

Desse sistema especial de proteção, assim como das basilares da nomeada Doutrina da proteção integral, decorrem as garantias denominadas "direito ao não-trabalho do menor de quatorze anos", e "direito ao trabalho protegido do adolescente entre os quatorze e dezoito anos de idade" (MACHADO, 2003, p. 173).

$\mathrm{O}$ artigo $7^{\circ}$, inciso XXXIII, da CF, dispõe a "proibição de trabalho noturno, perigoso ou insalubre a menores de dezoito e de qualquer trabalho a menores de dezesseis anos, salvo na condição de aprendiz, a partir de quatorze anos."

Daí extraem-se três preceitos: a) a proibição de qualquer trabalho ao menor de dezesseis anos; b) a exceção à regra do trabalho proibido ao menor de dezesseis anos na condição de aprendiz, a partir dos quatorze anos; e c) a proibição do trabalho noturno, perigoso ou insalubre ao menor de dezoito anos.

Endossando a previsão inserida no artigo $7^{\circ}$ do texto constitucional, o artigo $227, \S 3^{\circ}$, inciso I, da CF, positiva a "idade mínima de quatorze anos para admissão ao trabalho, observado o disposto no art. $7^{\circ}$, XXXIII." Nessa mesma linha, o artigo 60 do Estatuto da Criança e do Adolescente (ECA), reforça a proibição de qualquer trabalho ao menor de quatorze anos, ressalvando a hipótese de menor aprendiz.

Sequencialmente, o artigo 67 do diploma legal de proteção das crianças e adolescentes, de forma mais específica, elenca as proibições e restrições de trabalho aos menores de dezoito anos. $^{8}$

Nesse sentido, o trabalho infantil é contextualizado como aquele normativamente proibido de ser exercido por crianças e adolescentes, consoante previsões contidas no texto constitucional e nas legislações específicas.

\footnotetext{
${ }^{7}$ Essa expressão é utilizada para designar, parafraseando Martha Toledo Machado, o reconhecimento da especificidade das crianças e dos adolescentes como seres humanos que estão sendo construídos e desenvolvidos físico, psíquico e emocionalmente (MACHADO, 2003, p. 105).

${ }^{8}$ Art. 67. Ao adolescente empregado, aprendiz, em regime familiar de trabalho, aluno de escola técnica, assistido em entidade governamental ou não-governamental, é vedado trabalho: I - noturno, realizado entre as vinte e duas horas de um dia e as cinco horas do dia seguinte; II - perigoso, insalubre ou penoso; III - realizado em locais prejudiciais à sua formação e ao seu desenvolvimento físico, psíquico, moral e social; IV - realizado em horários e locais que não permitam a frequência à escola.
} 
Do ponto de vista dos documentos internacionais, ressalta-se a Convenção 182 e a Recomendação 190, ambas da OIT, as quais versam sobre a proibição das piores formas de trabalho infantil e a ação imediata para sua eliminação, promulgadas pelo direito interno brasileiro por meio do Decreto $\mathrm{n}^{\circ} 3.597$, de 12 de setembro de 2000.

A OIT, por meio da Convenção 138 e Recomendação 146, também atentou, além à erradicação do trabalho infantil, para a idade mínima de admissão ao trabalho aceitável ${ }^{9}$, entendimento que veio a ser inernalizado no Direito Brasileiro, na forma do Decreto $\mathrm{n}^{\circ}$ 4.134, de 15 de fevereiro de 2002.

Outrossim, encontram-se como um dos objetivos da Organização das Nações Unidas (ONU), no tópico 8.7, da Agenda Mundial $n^{\circ}$ 8, a qual trata sobre trabalho decente e crescimento econômico, assegurar a proibição do trabalho infantil e erradicá-lo até o ano de 2025 , em todas as suas formas. ${ }^{10}$

Para regulamentação dos textos internacionais da Convenção 182 e Recomendação 190 da OIT, instituiu-se no Brasil o Decreto $\mathrm{n}^{\mathrm{o}}$ 6.481, de 12 de junho de 2008. Tal regulamento traz algumas especificações no que toca ao trabalho protegido dos adolescentes e elenca as piores formas de trabalho infantil, as quais ficaram denominadas pela estrutura de Lista TIP.

A listagem é organizada por tabelamento, dividida por gêneros de atividades e indicando as hipóteses das piores formas de trabalho infantil, seguidos dos prováveis riscos ocupacionais e as prováveis repercussões à saúde da criança.

Dentre as hipóteses elencadas na Lista TIP encontram-se várias atividades relacionadas à agricultura, pecuária e exploração florestal, como o cultivo do fumo, extração e corte da madeira. Também são indicadas como piores formas de trabalho infantil, aquelas relacionadas à indústria da transformação, como a industrialização da cana-de-açúcar, produção do carvão vegetal, reciclagem de papel, plástico e metal. Incluem-se na lista, igualmente, trabalhos pesados envolvendo construção civil, assim como serviços domésticos de forma geral.

Além de todas as situações tabeladas na Lista TIP, o artigo $3^{\circ}$ da Convenção 182 da OIT, fundamenta que a expressão "piores formas de trabalho," compreende práticas criminosas

\footnotetext{
${ }^{9}$ Artigo $1^{\text {o: }}$ : Todo País-Membro em que vigore esta Convenção, compromete-se a seguir uma política nacional que assegure a efetiva abolição do trabalho infantil e eleve progressivamente, a idade mínima de admissão a emprego ou a trabalho a um nível adequado ao pleno desenvolvimento físico e mental do adolescente.

${ }^{10}$ 8.7 Tomar medidas imediatas e eficazes para erradicar o trabalho forçado, acabar com a escravidão moderna e o tráfico de pessoas, e assegurar a proibição e eliminação das piores formas de trabalho infantil, incluindo recrutamento e utilização de crianças-soldado, e até 2025 acabar com o trabalho infantil em todas as suas formas.
} 
como escravidão ou situações análogas, tráfico de crianças, recrutamento forçado de infantes para ser utilizados em conflitos armados, prostituição, produção de pornografia, utilização e recrutamento de crianças para atividades ilícitas, como o delito de tráfico de drogas, bem como demais trabalhos que possam prejudicar a saúde, segurança e a moral dos infantes. ${ }^{11}$

Esse aparato de normas protetivas tem razão de ser: o trabalho infantil gera danos às crianças e aos adolescentes a que a ele são submetidos, muitos deles irreparáveis. Precipuamente, considerando a peculiar condição de pessoa em desenvolvimento, é possível afirmar que crianças e adolescentes não possuem estrutura física e emocional para cumprirem uma jornada de trabalho comum a adultos ou, como em muitos casos, exaustivas até mesmo para esses últimos.

Essa situação compromete a organização psicológica da criança, refletindo no seu futuro, que muito provavelmente não terá uma estrutura emocional suficientemente equilibrada para lidar com as responsabilidades da vida, verdadeiramente, adulta (CAMPOS \& FRANCISCHINI, 2003, p. 123).

A criança, sendo um ser humano em desenvolvimento e, portanto, necessitando passar por experimentações de suas potencialidades individuais e das próprias curiosidades da vida advindas da natural ingenuidade, ao trabalhar, não por uma "experimentação," mas por necessidade, acaba entrando em conflito com outros interesses relativos à construção da sua personalidade (MACHADO, 2003, p. 177).

O cumprimento de uma jornada de trabalho diária, por seu turno, também impede o estudo pela criança, pois usufrui de força física, necessária para a frequência na escola, além de limitar seu desempenho, uma vez que o tempo de estudo se torna muito limitado, ou inexistente. Esse acúmulo de tarefas acaba por prejudicar o potencial profícuo das crianças e adolescentes, fadando muitos a um futuro em condição de indigência (MACHADO, 2003, pp. 177-178).

\footnotetext{
${ }^{11}$ Artigo $3^{\circ}$. Para os fins desta Convenção, a expressão as piores formas de trabalho infantil compreende: a) todas as formas de escravidão ou práticas análogas à escravidão, comovenda e tráfico de crianças, sujeição por dívida, servidão, trabalho forçado ou compulsório, inclusive recrutamento forçado ou obrigatório de crianças para serem utilizadas em conflitos armados; b) utilização, demanda e oferta de criança para fins de prostituição, produção de pornografia ou atuações pornográficas; c) utilização, recrutamento e oferta de criança para atividades ilícitas, particularmente para a produção e tráfico de entorpecentes conforme definidos nos tratados internacionais pertinentes; d) trabalhos que, por sua natureza ou pelas circunstâncias em que são executados, são suscetíveis de prejudicar a saúde, a segurança e a moral da criança.
} 
Por uma ótica ainda mais gravosa do que o comprometimento escolar e futuro profissional, tem-se os riscos que o trabalho precoce causa à saúde das crianças e adolescentes. $\mathrm{O}$ trabalho exige parâmetros muito superiores à condição de crescimento que as crianças se encontram, limitando o próprio desenvolvimento físico delas (MACHADO, 2003, p. 178).

Adicionado à debilitação física, estão um estado de fadiga, ausência de disposição (e de tempo) para outras atividades, como brincar, além do eventual déficit de atenção e restrição das relações sociais. Salienta-se, por oportuno, que o ato de "brincar," ao exemplo, é atividade essencial ao desenvolvimento dos infantes, pois matura suas necessidades e trabalha com os desejos que não possuem possibilidade de efetivação na realidade (CAMPOS \& FRANCISCHINI, 2003, p. 123).

Além dos prejuízos ao desenvolvimento cognitivo e a incompatibilidade da personalidade infanto-juvenil com uma disciplina rígida de trabalho, assinalam-se outros pontos preocupantes do labor precoce, como exposição dos infantes a atividade insalubre, risco de acidentes de trabalho, advindos do próprio fator de risco do trabalho, mas sobremaneira em razão da própria condição dos infantes, os quais não possuem capacidade mental totalmente formada para medir prudência. Nesse sentido, Martha Toledo Machado:

\footnotetext{
O trabalho precoce compromete a saúde de crianças e adolescentes, seja pelas condições de insalubridade de muitas atividades, seja pelo potencial de risco de acidentes contido no trabalho; risco que é muito mais elevado para crianças e adolescentes, seja pelo seu não-domínio completo das habilidades motoras típicas do adulto, inerente no seu estágio de crescimento, seja pela imprudência típica da infância e da adolescência, já que crianças e adolescentes estão ainda aprendendo e construindo a prudência do ser humano adulto, parte do que passa, necessariamente, pela construção da autodisciplina (MACHADO, 2003, p. 178).
}

Infelizmente, a realidade pesa sobre toda a gama de Direitos Humanos e Fundamentais protecionistas das crianças e adolescentes, proibitivos do trabalho infantil e asseguradores do direito ao trabalho protegido do adolescente.

Como antes mencionado, o Brasil abriga mais de 2 (dois) milhões de crianças e adolescentes em situação de trabalho infantil, simbolizando número expressivo diante daqueles 153 milhões de infantes submetidos à exploração do trabalho infantil no mundo.

Ocorre que, mesmo com a existência de normas protetivas, o trabalho infantil ainda é muito presente na sociedade brasileira, desenvolvendo-se diariamente aos olhos de todos, mas que a comodidade impede de enxergar, sendo preferível que uma criança esteja coletando 
latinhas nas ruas durante o horário escolar, por exemplo, do que cometendo crimes. Como se essas duas situações fossem excludentes ou relacionadas.

Dessa forma, propõe-se na etapa seguinte da presente pesquisa contrapor o trabalho infantil a partir dos dados que contextualizam seu quadro fático. Porém, o tema será analisado pelas lentes de um velho e persistente problema, o qual, ao ver deste estudo, muito assemelhase ao trabalho infantil: o trabalho escravo.

\section{TRABALHO ESCRAVO: O CERNE DO LABOR PRECOCE}

Apesar da escravidão ter sido abolida formalmente no Brasil há mais de cento e trinta anos, essa grave violação de Direitos Humanos persiste em solo brasileiro e no mundo, apresentando-se em formas contemporâneas.

O índice denominado The Global Slavery Index 2016, organizado pela ONG Walk Free Foundation, validado pela OIT, aponta que mais de 45.8 milhões de pessoas, em 167 nações, vivem em regime de escravidão. ${ }^{12}$ No Brasil, segundo o mesmo indicador, mas atualizado ao ano de 2018, estima-se que existam 369 mil pessoas submetidas ao trabalho escravo. ${ }^{13}$

Em termos de parâmetro conceitual, no Brasil, o vetor para configuração do trabalho escravo contemporâneo é o artigo 149 do Código Penal, o qual tem na escravidão por dívida, no trabalho forçado, nas jornadas exaustivas e em condições degradantes de trabalho, os elementos caracterizadores do crime de trabalho análogo ao de escravo. ${ }^{14}$

O fenômeno, sobretudo, é muito mais flexível e mutável do que sua histórica versão antecessora, descartando pessoas na mesma medida em que as alicia, tornando-se um modo extremo de exploração econômica (NINA, 2010, pp. 90-91).

\footnotetext{
12 WALK FREE FOUNDATION. The Global Slavery Index 2016. Disponível em: <https://www.globalslaveryindex.org/resources/downloads/>. Acesso em 1 abr. 2020.

13 WALK FREE FOUNDATION. The Global Slavery Index 2018. Disponível em: <https://www.globalslaveryindex.org/2018/data/country-data/brazil/>. Acesso em 31 mar. 2020.

${ }^{14}$ Art. 149. Reduzir alguém a condição análoga à de escravo, quer submetendo-o a trabalhos forçados ou a jornada exaustiva, quer sujeitando-o a condições degradantes de trabalho, quer restringindo, por qualquer meio, sua locomoção em razão de dívida contraída com o empregador ou preposto: Pena - reclusão, de dois a oito anos, e multa, além da pena correspondente à violência.
} 
Da mesma maneira, ao trabalho escravo contemporâneo não importa a raça do escravo, como ocorria na escravidão antiga e histórica ${ }^{15}$, apenas as vantagens da exploração da sua mão de obra. No Brasil, as vítimas do trabalho escravo são, em regra, pessoas advindas de locais de extrema pobreza, como Norte e Nordeste brasileiros, bem como imigrantes vindos de outras nações da América Latina, estes últimos frequentemente explorados em oficinas de costuras (NINA, 2010, pp. 135-136).

As vítimas caracterizam-se por serem pessoas analfabetas ou com poucos anos de estudo, sendo principalmente recrutadas em municípios de baixo IDH, como nos Estados do Maranhão, Piauí, Tocantins e Pará (AUDI, 2006, p. 77).

Portanto, se está diante de um fenômeno que visa única e exclusivamente as vantagens de uma exploração econômica cruel e desenfreada, a qual vitimiza pessoas em situação de extrema pobreza e alta vulnerabilidade. É nesse ponto que se vislumbra no trabalho infantil um reflexo do trabalho escravo.

No contexto do trabalho infantil brasileiro, uma pesquisa empírica realizada num município do Rio Grande do Norte observou que diante da situação de carência em que as famílias entrevistadas estavam inseridas, o trabalho infantil era algo já consolidado e não questionável. Mais, é algo solicitado, como se fosse naturalmente esperado e passível de aceitação sem maiores questionamentos (CAMPOS \& FRANCISCHINI, 2003, p. 122).

Contabilizando-se mais de 2 milhões de crianças e adolescentes em situação de trabalho infantil no Brasil, segundo o PNAD 2015, a maior parte dessa população encontra-se na faixa etária entre os 5 e 17 anos de idade, estando distribuída, na sua maioria, pelo Nordeste e Sudeste brasileiros, com 852 e 854 mil infantes em trabalho infantil, respectivamente. Em seguimento, estão as regiões Sul, Norte e Centro-Oeste, contando, em ordem sequencial, com 432, 311 e 223 mil crianças e adolescentes ocupados.

Desses números, indica-se que 59\% das crianças e adolescentes são meninos, ao passo que os outros $41 \%$ compõem-se por meninas. Entretanto, segundo o Fórum Nacional de Prevenção e Erradicação do Trabalho Infantil (FNPETI), quando se trata de trabalho doméstico, as meninas são a maioria $(94,2 \%)$. Outrossim, a maior incidência de trabalho

\footnotetext{
${ }^{15}$ Por escravidão antiga entende-se aquela ocorrida entre a Antiguidade Clássica até o século XV (NINA, 2010, p. 38). Já por escravidão histórica temos o sistema escravocrata presente no mundo pelo período compreendido entre o século XV até o fim do século XIX (NINA, 2010, p. 57).
} 
infantil concentra-se na faixa etária de 14 e 17 anos, expressando 83,7\% do total de ocupação infanto-juvenil.

Com relação à etnia, de acordo com o FNPETI o número de crianças e adolescentes negros trabalhando é maioria (1.4 milhão), sendo que as regiões Nordeste e Sudeste são as que apresentam o maior índice de infanto-juvenis negros trabalhando.

Em termos de domicílio, o FNPETI aduz que na área rural há 976 mil crianças e adolescentes em trabalho infantil, ao passo que nas regiões urbanas o número é de 1.4 milhão. Porém, entre os infantes de mais tenra idade (5 e 13 anos), o meio rural é predominante (308 mil na zona agrícola e 143 mil nas cidades).

Na demografia brasileira, ainda segundo o PNAD 2016, a predominância do trabalho infantil apresenta-se, com exceção da região Norte, em atividades laborais não agrícolas, como comércio, construção e serviços domésticos.

No ponto, de acordo com o mapa do trabalho infantil da ONG Rede Peteca, deve ser assinalado que, dentre o número de 2.7 milhões de crianças e adolescentes em situação de trabalho infantil, uma parcela encontra-se em condição de aprendiz ou trabalho permitido.

Apesar da imprecisão de dados, tendo como parâmetro pesquisa feita pelo FNPETI, o percentual de adolescentes trabalhando de forma regular no Brasil é de $15 \%$ em relação ao indicativo geral de infantes em labor precoce. Portanto, a ONG Rede Peteca conclui que 406 mil adolescentes estão trabalhando de modo legalmente permitido no Brasil.

Especificamente, no tocante à predominância do trabalho infantil por gênero de atividades, em pesquisa filtrada no mapa do trabalho infantil da ONG Rede Peteca, obteve-se os seguintes dados: a) no ramo da Administração Pública, educação, saúde, serviços sociais, coletivos e pessoais, existem aproximadamente 286.303 mil crianças e adolescentes em situação de trabalho infantil; b) já no âmbito da agricultura, pecuária, silvicultura, pesca e aquicultura, estima-se que existam 1.024,403 milhão de infantes trabalhadores; c) nas atividades ligadas ao comércio e reparação, o indicador aponta o número de 795.466 mil crianças e adolescentes em trabalho infantil; d) no âmbito das atividades laborais de construção, contabilizam-se 462.876 mil crianças e adolescentes trabalhadoras; e) na indústria da transformação, extração mineral, petróleo, gás, eletricidade e água, estima-se a predominância de 356.129 mil crianças e adolescentes em situação de trabalho infantil; f) nos serviços de alojamento, alimentação, transportes, financeiros e imobiliários, aponta-se a existência de 461.425 mil infantes trabalhando; g) relativo ao trabalho infantil nos serviços 
domésticos, o indicador é de 174.826 mil; h) o restante da relação trata do grupo intitulado como "atividades mal definidas" do trabalho infantil, as quais contabilizam 1.568 mil, distribuídas entre os estados do Pará, Pernambuco e Alagoas.

O FNPETI, por sua vez, menciona que, em todas as faixas etárias, possuem destaques os trabalhos na agricultura e na pecuária, criação de gado, vendas como ambulantes e a domicílio, ajudantes de cozinha, balconistas, cuidadores de crianças, recepcionistas e trabalhos elementares na construção civil. Entre os 5 e 13 anos de idade, faixas etárias nas quais o trabalho é totalmente proibido, há predominância do trabalho agrícola. Em contrapartida, entre os adolescentes inseridos na faixa etária de 16 a 17 anos de idade, o domínio é das ocupações urbanas, como escriturários gerais, balconistas e vendedores de lojas.

Outro tipo de trabalho infantil extremamente recorrente no Brasil, mas que parece ser visto pouco como tal, é aquele ligado ao crime de tráfico de drogas. Nesse diapasão, uma pesquisa feita pelo Núcleo de Etnografias Urbanas do Centro Brasileiro de Análise e Planejamento (CEBRAP), analisou o tráfico de drogas como uma das piores formas de trabalho infantil.

No estudo, os pesquisadores levantaram a incongruência presente em punir como autor de um ato infracional o adolescente que pratica o crime de tráfico de drogas, mas não considerálo uma vítima de uma das piores formas de trabalho infantil. Também, na pesquisa, os estudiosos acompanharam a trajetória de quatorze adolescentes inseridos no contexto do tráfico de drogas, observando grande evasão escolar e reconfigurações familiares forçadas por conta de prisão ou homicídios de parentes.

Nessa linha de vulnerabilidade social que parece impulsionar o trabalho infantil, é que tal violação de Direitos Humanos e Fundamentais parece assemelhar-se à escravidão e, a ela, muitas vezes, conectar-se.

De acordo com o Ministério Público do Trabalho (MPT), no seu Observatório Digital do Trabalho Escravo, aponta-se que entre os anos de 2003 e 2018, aproximadamente 938 crianças foram resgatadas em condições análogas à escravidão.

Ainda, o número de acidentes de trabalho com crianças e adolescentes no Brasil é exorbitante, ao passo que o Sistema de Informação de Agravo de Notificação (SINAN), do Ministério da Saúde, aponta que entre os anos de 2007 e 2018, ocorreram quase 44 mil acidentes de trabalho com crianças e adolescentes, contando idades entre os 5 e 17 anos de 
idade. Desse indicador, cerca de 261 infantes perderam a vida trabalhando. É inequívoco, portanto, as condições de trabalho indignas que o labor infantil representa.

Além disso, em dados obtidos pela ONG “Escravo nem Pensar!”, observou-se que pessoas acostumadas com o trabalho precário precocemente, são mais suscetíveis a serem exploradas pelo trabalho escravo quando adultas. Outrossim, somado às presenças de crianças e adolescentes nos resgates de vítimas da escravidão contemporânea, o estudo formulado pela organização suprarreferida também destaca que, entre vítimas do trabalho escravo libertadas no Pará, Mato Grosso, Bahia e Goiás (em 2006 e 2007), aproximadamente 121 dessas afirmaram terem começado a trabalhar desde os 11 anos de idade.

Pode-se dizer, afinal, que o trabalho infantil de fato está enraizado nas entranhas da escravidão. Não somente em razão da alta vulnerabilidade, pobreza e precariedade que o labor infantil envolve, mas pela própria questão da liberdade de escolha suprimida, uma vez que as violações normalmente ocorrem por conta das famílias dos infantes já estarem inseridas numa relação de trabalho que as explora, culminando na privação da liberdade da criança e do adolescente que acaba sendo forçado a esse ciclo vicioso (SEN, 2010, p. 48).

Ainda, os dados que retratam o contexto do trabalho infantil, denotam que o labor precoce se encontra consolidado na realidade brasileira, com expressivo número nas regiões agrícolas, mas também em setores como construção, comércio e serviços domésticos. Além disso, não há como deixar de citar a esmagadora maioria de crianças e adolescentes negros em situação de trabalho infantil.

Diante desse alarmante cenário, no tópico a seguir abordar-se-à as principais ações para o combate do trabalho infantil no Brasil.

\section{AS AÇÕES DE COIBIÇÃO AO TRABALHO INFANTIL NO BRASIL}

Verificou-se no decorrer deste estudo como o trabalho infantil ainda predomina em solo brasileiro de forma muito significativa, analisando suas características como fenômeno violador de Direitos Humanos e Fundamentais, e sua forte relação com o trabalho escravo, porquanto se tratar da mesma engrenagem relacionada à manutenção da pobreza e marginalização de pessoas inseridas em um contexto social vulnerável. Disso, aventa-se o seguinte questionamento: como coibir e buscar erradicar essa prática? 
A Constituição Federal de 1988, ressalvadas todas as opiniões em contrário, de fato é um marco histórico importante na forma de se pensar em trabalho infantil no Brasil, visto que abarca normas proibitivas num contexto social que ainda vivia sob o regimento do famigerado Código de Menores de 1979. Após isso, o Estado Brasileiro começaria a viver uma nova era no tratamento do trabalho infantil em seu território.

No ano de 1994 foi criado o Fórum Nacional de Prevenção e Erradicação do Trabalho Infantil (FNPETI), bastante referido na etapa anterior desta pesquisa, tratando-se de uma estratégia para articular e aglutinar as principais instituições envolvidas com políticas e programas de prevenção e erradicação do trabalho infantil. O FNPETI possui apoio da OIT e do Fundo das Nações Unidas para a Infância (UNICEF).

A entidade é conceituada como um espaço democrático e não institucionalizado, aberto à discussão de propostas, definição de estratégias e construção de consensos em conjunto ao governo e a sociedade. Além disso, a FNPETI coordena a Rede Nacional de Combate ao Trabalho Infantil, sendo essa composta por 27 Fóruns de Erradicação do Trabalho Infantil e Proteção ao Adolescente Trabalhador e por outras 48 entidades relacionadas à causa.

Dentre os vários objetivos do FNPETI, constam a busca pelo cumprimento dos dispositivos legais e das convenções internacionais ratificadas pelo Brasil, referente à temática do trabalho infantil, contribuição na elaboração de políticas públicas, programas e ações de prevenção e erradicação do trabalho infantil e proteção ao adolescente, defender a garantia dos direitos fundamentais e humanos de crianças e adolescentes e a proteção contra o trabalho infantil. Até mesmo, compõem o rol de objetivos a promoção de estratégias de sensibilização com o fito de desconstruir e mudar os padrões simbólico-culturais que naturalizam o labor infantil, além da participação de crianças e adolescentes nos espaços de discussão e deliberação sobre seus direitos.

Nesse sentido, o então Ministério do Trabalho e Emprego, por intermédio da Portaria $\mathrm{n}^{\circ}$ 952 de 8 de julho de 2003, instituiu a Comissão Nacional de Erradicação do Trabalho Infantil (CONAETI), a qual possuía como um dos seus objetivos a implementação, por meio de políticas públicas, das disposições da OIT para prevenção e erradicação do trabalho infantil.

Também constavam como objetivos da CONAETI, a criação de mecanismos para o monitoramento dessas ações, assim como a criação do Plano Nacional de Combate ao Trabalho Infantil. 
Entretanto, a CONAETI acabou sendo extinta em 21 de agosto de 2019, por meio da Portaria $\mathrm{n}^{\mathrm{o}} 972$ do Ministério da Economia, a qual revogou setenta documentos protetores dos direitos trabalhistas, dentre eles, o GT sobre trabalho escravo. ${ }^{16}$

No ponto, sinala-se que a CONAETI havia lançado o III Plano Nacional de Prevenção e Erradicação do Trabalho Infantil e Proteção ao Adolescente Trabalhador (2019-2022), o qual traz o seguinte conceito de trabalho infantil:

O termo "trabalho infantil" refere-se às atividades econômicas e/ou atividades de sobrevivência, com ou sem finalidade de lucro, remuneradas ou não, realizadas por crianças ou adolescentes em idade inferior a 16 (dezesseis) anos, ressalvada a condição de aprendiz a partir dos 14 (quatorze) anos, independentemente da sua condição ocupacional.

Destaca-se que toda atividade realizada por adolescente trabalhador, que, por sua natureza ou pelas circunstâncias em que é executada, possa prejudicar o seu desenvolvimento físico, psicológico, social e moral, se enquadra na definição de trabalho infantil e é proibida para pessoas com idade abaixo de 18 (dezoito) anos.

Entre os dados inseridos no documento, salta aos olhos a análise da renda familiar das crianças e adolescentes, entre os cinco e 17 anos de idade, submetidas ao trabalho infantil, conforme pode ser observado na tabela abaixo:

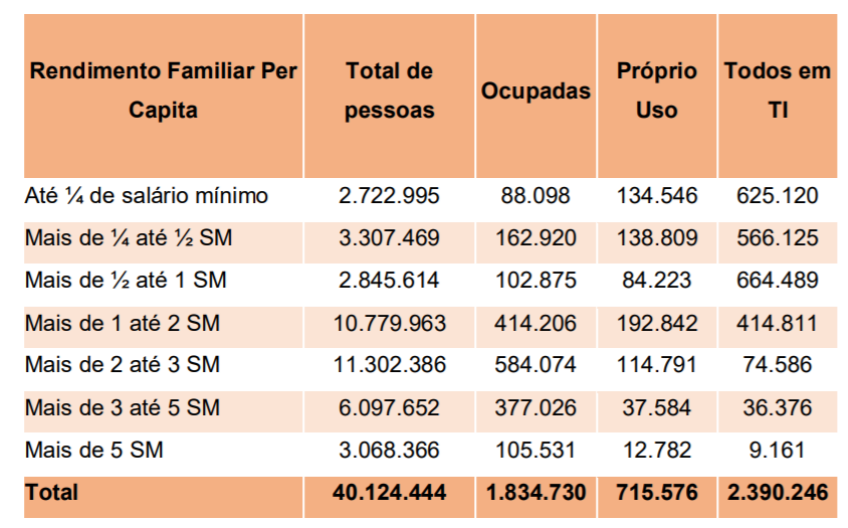

Fonte: IBGE - PNAD Contínua, 2016.

Dessa apresentação, verifica-se que a maioria das crianças e adolescentes em situação de trabalho precoce está inserida em famílias que percebem renda per capita inferior a um salário mínimo.

\footnotetext{
${ }^{16}$ BRASIL. Portaria ${ }^{\circ}$ 972, de 21 de agosto de 2019. Disponível em: < http://www.in.gov.br/en/web/dou//portaria-n-972-de-21-de-agosto-de-2019-211908255>. Acesso em 1 abr. 2020.
} 
No que toca aos objetivos do Plano de Prevenção e Erradicação em comento, o documento conta com sete eixos estratégicos: a) priorização da prevenção e erradicação do trabalho infantil e proteção ao adolescente trabalhador nas agendas políticas e sociais; b) promoção de ações de comunicação e mobilização social; c) criação, aperfeiçoamento e implementação de mecanismos de prevenção e erradicação do trabalho infantil e proteção ao adolescente trabalhador, com destaque para as piores formas; d) promoção e fortalecimento da família na perspectiva de sua emancipação e inclusão social; e) garantia de educação pública de qualidade para todas as crianças e os adolescentes; f) proteção da saúde de crianças e adolescentes contra a exposição aos riscos do trabalho; e g) fomento à geração de conhecimento sobre a realidade do trabalho infantil no Brasil, com destaque para as suas piores formas.

Para concretização desses objetivos, os quais visavam a acelerar o processo de erradicação do trabalho infantil e a garantia do direito à educação, no documento em tela foram inseridas matrizes operacionais para cumprimento de metas e parcerias com diversos órgãos, como o MPT, MEC, OIT, etc. Contudo, com a extinção do Ministério do Trabalho e sua supressão como Secretaria, além da revogação da própria CONAETI, os objetivos do plano de erradicação do trabalho infantil significam não mais que mera tinta no papel.

De outro lado, ressalta-se a atuação do Ministério Público do Trabalho (MPT) no combate ao trabalho infantil. O órgão estima receber cerca de 4.3 mil denúncias de trabalho infantil por ano, sendo que entre os anos de 2014 e 2018, foram registradas 21.551 ocorrências relacionadas à exploração do trabalho precoce. Apenas nesse lapso temporal, o MPT ajuizou 968 ações e firmou 5.990 Termos de Ajustamento de Conduta. ${ }^{17}$

Para atuação contra o trabalho infantil, a instituição criou a Coordenação Nacional de Combate à Exploração do Trabalho da Criança e do Adolescente (Coordinfância), consistindo em uma das áreas temáticas do MPT, a qual trata especificamente da erradicação do trabalho infantil e da regularização do trabalhador adolescente. As ações são manejadas mediante um membro representante da Coordinfância por estado brasileiro.

\footnotetext{
${ }^{17}$ MINISTÉRIO PÚBLICO DO TRABALHO. Dia Mundial de Combate ao Trabalho Infantil: MPT recebe em média 4,3 mil denúncias por ano. MPT. 11 jun. 2019. Disponível em: <https://mpt.mp.br/pgt/noticias/diamundial-de-combate-ao-trabalho-infantil-mpt-recebe-em-media-4-3-mil-denuncias-por-ano>. Acesso em 1 abr. 2020.
} 
Nesse sentido, é o projeto chamado "Resgate à Infância," que atua em três eixos: educação, políticas públicas e aprendizagem. A partir disso, foi criado o "MPT na Escola," o qual visa a comunidade escolar, buscando a conscientização de professores, pais e alunos sobre o trabalho infantil, a fim de multiplicar as ações de combate e conscientização.

Atualmente, o MPT maneja a campanha nacional intitulada "Toda Criança é Nossa Criança. Diga não ao Trabalho Infantil," lançada no dia 12 de junho de 2019, data que representa o Dia Mundial de Combate ao Trabalho Infantil.

"Você acha difícil imaginar o quanto é ruim para uma criança ficar vendendo coisas na rua? Comece imaginando que é o seu filho," é o que alertam as frases constantes nas peças da campanha, a qual está sendo propagada nas redes sociais por meio de vídeos e flyers.

É notório que o principal objetivo da campanha é alertar e conscientizar uma sociedade que atesta e legitima o trabalho infatil, não somente como algo natural, mas benéfico e pedagógico a crianças e adolescentes. $\mathrm{O}$ curioso é que tal regra parece valer apenas para uma parcela específica da sociedade, já que os infantes inseridos em núcleos familiares de acentuado poder aquisitivo, comumente, apenas saem para trabalhar após ingressarem na faculdade.

Esse imaginário social, inclusive, muito assemelha-se às políticas jurídico-assistenciais praticadas nas primeiras décadas do século XX, com discurso centrado no objetivo de "salvar a criança" para transformação do Brasil (RIZZINI, 2011, p. 27).

No âmbito da luta contra o trabalho infantil, destacam-se fortemente, da mesma forma como ocorre com o trabalho escravo, a atuação das organizações não-governamentais.

A ONG Rede Peteca, a sua vez, é um desses exemplos. Com o slogan "Chega de Trabalho Infantil," a iniciativa foi lançada em 26 de setembro de 2016, resultante de uma parceria entre a Associação Cidade Escola Aprendiz, o MPT e a Associação para o Desenvolvimento dos Municípios do Estado do Ceará (APDMCE).

A organização atua principalmente por meio da comunicação, utilizando da sua plataforma digital, visando a promoção dos direitos da criança e do adolescente, e a erradicação do trabalho infantil. Estruturada por uma rede intersetorial de ações e objetivos, a Rede Peteca busca disseminar informações relevantes sobre a temática, por meio de campanhas, reportagens, colunas e materiais de apoio disponíveis gratuitamente na internet.

Uma iniciativa louvável da organização, em meio à imprecisão de dados que os temas relacionados aos direitos da criança e adolescente enfrentam no Brasil, foi a criação do "Mapa 
do Trabalho Infantil," o qual unifica diversas informações sobre o labor precoce, sendo possível a coleta de dados mais precisos por cada região do País, propiciando, assim, a disseminação de informações sobre o trabalho infantil em busca da conscientização e mudança na cultura da população.

$\mathrm{Na}$ esteira do direito à profissionalização e como uma medida para evitar a evasão escolar adolescente, mas, ao mesmo tempo, pensando nas necessidades financeiras e contexto familiar do adolescente que procura pelo trabalho, está o Programa Aprendiz Legal ou Jovem Aprendiz, regulamentado pela Lei $\mathrm{n}^{\circ} 10.097$, de 19 de dezembro de 2000.

O diploma legal prevê que empresas de médio e grande porte contratem jovens entre as idades de 14 e 24 anos como aprendizes. Na hipótese, é formalizado um contrato de trabalho especial, o qual tem duração de até dois anos, ao passo que, nesse período, o jovem é capacitado pela instituição formadora e empresa, cumulando o conhecimento teórico à prática. A validade do contrato de aprendizagem é condicionada à matrícula e à frequência do aprendiz na escola, sendo garantido a ele um salário mínimo-hora.

Em meio a ações para prevenção e adoção de medidas para erradicação do trabalho infantil, além das buscas pelo aperfeiçoamento do direito ao trabalho protegido do adolescente, segundo o PNAD 2015, entre os anos de 1992 e 2015, cerca de 5.7 milhões de crianças deixaram de trabalhar no Brasil, o que significa uma redução de $68 \%$ no percentual de infantes em labor precoce.

Nada obstante a essa grande mudança no quadro fático do trabalho infantil, a qual demonstra acentuado avanço na sua erradicação, a realidade atual é a existência de mais de dois milhões de crianças e adolescentes em situação de trabalho proibido ou irregular, devendo a busca pela aceleração no processo de erradicação e prevenção do trabalho infantil compor uma das pautas principais do Estado e da sociedade brasileira.

\section{CONSIDERAÇÕES FINAIS}

No desenvolvimento da presente pesquisa, analisou-se que o trabalho infantil se trata de uma violação de direitos básicos daqueles que uma sociedade e um Estado juraram constitucionalmente zelar: crianças e adolescentes.

O problema não atinge tão somente o Brasil, mas o mundo inteiro, tendo-se índices exorbitantes de crianças em situação de labor precoce ao redor do globo. 
No nosso país, a proibição do trabalho infantil vem consolidada no texto constitucional e corroborada pelas legislações ordinárias, ao passo que há abertura para um direito ao trabalho protegido para adolescentes entre os 16 e 18 anos de idade, além da possibilidade de exercer funções como aprendiz a partir dos 14 anos. Além do mais, as proibições do trabalho infantil vem inseridas nos documentos internacionais, como as convenções da OIT, específicas do tema.

Os regramentos possuem razão de ser, visto que o trabalho e a rigidez da sua disciplina são extremamente incompatíveis com a condição infanto-juvenil.

De mais a mais, tem-se que as condições usualmente normais ao trabalho infantil são precárias, acarretando em graves riscos de acidentes de trabalho e à vida dos infantes, ao passo que o Brasil têm índices elevadíssimos de crianças e adolescentes que se lesionam laborando.

Concluiu-se neste estudo, por seu turno, haver forte relação do trabalho infantil com o trabalho escravo propriamente dito, sendo possível afirmar que as raízes do labor precoce repousam em muito nas margens da escravidão.

O perfil das crianças e adolescentes em situação de trabalho infantil no Brasil repete-se: a maioria deles são advindos de famílias que percebem renda per capita inferior a um salário mínimo. O tipo de ocupações a que são designados também são recorrentes: agricultura, pecuária, vendas ambulantes nas zonas urbanas, serviços domésticos e construção civil, além de crianças e adolescentes utilizados para comercialização de drogas.

Em ligação direta ao trabalho escravo, especialmente relacionada ao perfil das vítimas, nota-se a presença de crianças e adolescentes resgatados em ações de libertação de ofendidos do crime, somado ao fato de que parcela dos explorados pelo sistema escravagista contemporâneo são oriundos de um passado marcado pelo trabalho infantil.

Tem-se, portanto, um instrumento de exploração econômica precoce, servil a um ciclo vicioso para manutenção da pobreza e vulnerabilidade.

No âmbito do combate ao trabalho infantil no Brasil, destacam-se o Fórum Nacional de Prevenção e Erradicação do Trabalho Infantil (FNPETI), Comissão Nacional de Erradicação do Trabalho Infantil (CONAETI), o Ministério Público do Trabalho (MPT) e ONG's que tratam da temática. 
É inequívoco que o trabalho infantil brasileiro teve uma redução significativa em seu percentual de predominância, principalmente a partir da década de 90 , no período pósConstituição Federal de 1988.

Entretanto, o labor infantil ainda persiste, em um número demasiado, ao passo que muito já se avançou, mas muito ainda precisa ser acelerado, devendo ser adotadas cada vez mais medidas para erradicação e prevenção dessa prática.

Ainda mais importante que avançar, é a manutenção da preservação dos direitos conquistados, evitando-se qualquer tipo de retrocesso, o que se tornou um grande desafio frente à atual política praticada no Brasil, com a supressão do Ministério do Trabalho e revogação de outros importantes órgãos pelo Poder Executivo, como a CONAETI.

Além do problema em si, também é necessário atentar-se para as razões e origens do trabalho infantil, verificando-se o porquê de uma criança estar inserida numa situação laboral incompatível com sua condição peculiar de pessoa em desenvolvimento, com riscos tão acentuados à saúde dos infantes.

Outrossim, fazer-se-à impositiva uma mudança cultural no imaginário social sobre o trabalho infantil, desmistificando aquele velho discurso de ser preferível uma criança trabalhando, do que delinquindo, para entender que, tanto um, quanto outro, não passam de uma grave subtração de Direitos Humanos e Fundamentais dos infantes.

\section{REFERÊNCIAS}

AUDI, Patrícia. A escravidão não abolida. In: VELLOSO, Gabriel; FAVA, Marcos Neves (Coord.). Trabalho Escravo Contemporâneo: o desafio de superar a negação. 1.ed. São Paulo: LTR, 2006.

BRASIL. Aprendiz Legal. Disponível em: <http://site.aprendizlegal.org.br/>. Acesso em 1 abr. 2020.

BRASIL. Constituição da República Federativa do Brasil de 1988. Disponível em: <http://www.planalto.gov.br/ccivil_03/constituicao/constituicao.htm>. Acesso em 02 abr. 2020. 
BRASIL. Decreto-lei $\mathbf{n}^{\circ} \mathbf{2 . 8 4 8}$, de 7 de dezembro de 1940. Código Penal. Disponível em: <http://www.planalto.gov.br/ccivil_03/decreto-lei/del2848compilado.htm>. Acesso em: 02 abr. 2020.

BRASIL. Decreto $\mathbf{n}^{\mathbf{0}} \mathbf{6 . 4 8 1}$, de 12 de junho de 2008 . Disponível em: <http://www.planalto.gov.br/ccivil_03/_Ato2007-2010/2008/Decreto/D6481.htm>. Acesso em: 02 abr. 2020.

BRASIL. Lei no 8.069, de 13 de julho de 1990. Estatuto da Criança e do Adolescente. Disponível em: <http://www.planalto.gov.br/ccivil_03/leis/18069.htm>. Acesso em: 02 abr. 2020.

BRASIL. Lei $\mathbf{n}^{\mathbf{1 0}} \mathbf{1 0 . 0 9 7}$, de 19 de dezembro de 2000. Disponível em: <http://www.planalto.gov.br/ccivil_03/leis/110097.htm>. Acesso em: 02 abr. 2020.

BRASIL. III Plano Nacional de Prevenção e Erradicação do Trabalho Infantil e Proteção ao Adolescente Trabalhador (2019-2022). Disponível em: <https://fnpeti.org.br/media/documentos/III_Plano_PETI_-_2019_-_2022.pdf>. Acesso em 01 abr. 2020 .

BRASIL. Portaria $\mathbf{n}^{\mathbf{0}} 952$ de 8 de julho de 2003. CONAETI. Disponível em: <http://ilo.org/dyn/natlex/docs/ELECTRONIC/64483/105986/F1043089630/BRA64483.pdf> . Acesso em 01 abr. 2020.

CAMPOS, Herculano Ricardo; FRANCISCHINI, Rosângela. Trabalho Infantil Produtivo e Desenvolvimento Humano. Revista Psicologia em Estudo. Maringá, v. 8, n. 1, p. 119-129, jan./jun. 2003. Disponível em: <http://www.scielo.br/scielo.php?pid=S141373722003000100015\&script=sci_arttext $>$. Acesso em: 02 abr. 2020.

CEBRAP. Tráfico de Drogas entre as Piores Formas de Trabalho Infantil: mercados, famílias e rede de proteção social. NEU - Núcleo de Etnografias Urbanas, 2017. Disponível em:<http://cebrap.org.br/wpcontent/uploads/2017/04/Apresentacao_NEUFUMCAD_Final.pd f>. Acesso em 02 abr. 2020.

FNPETI. Fórum Nacional de Erradicação e Prevenção do Trabalho Infantil. Disponível em: <https://fnpeti.org.br/>. Acesso em: 02 abr. 2020.

IBGE. Pesquisa Nacional por Amostra de Domicílios Contínua (PNAD). Trabalho Infantil $2016 . \quad$ Disponível em: <https://biblioteca.ibge.gov.br/visualizacao/livros/liv101388_informativo.pdf>. Acesso em: 02 abr. 2020.

MACHADO, Martha Toledo. A Proteção Constitucional de Crianças e Adolescentes e os Direitos Humanos. Barueri: Manole, 2003.

MINISTÉRIO PÚBLICO DO TRABALHO. Coordinfancia. Disponível em: <https://mpt.mp.br/pgt/areas-de-atuacao/coordinfancia>. Acesso em: 02 abr. 2020. 
MINISTÉRIO PÚBLICO DO TRABALHO. Dia Mundial de Combate ao Trabalho Infantil: MPT recebe em média 4,3 mil denúncias por ano. MPT. 11 jun. 2019. Disponível em: $<$ https://mpt.mp.br/pgt/noticias/dia-mundial-de-combate-ao-trabalho-infantil-mpt-recebe-emmedia-4-3-mil-denuncias-por-ano>. Acesso em 02 abr. 2020.

MINISTÉRIO PÚBLICO DO TRABALHO. Documentário Ser Criança: um olhar para a infância e a juventude diante do trabalho no Brasil. Transe Filmes: 2018. Disponível em: <https://www.youtube.com/watch?v=yZnNN71rs2s>. Acesso em 02 abr. 2020.

MINISTÉRIO PÚBLICO DO TRABALHO. Observatório da Erradicação do Trabalho Escravo e do Tráfico de Pessoas. Disponível em: 〈https://smartlabbr.org/trabalhoescravo>. Acesso em 02 abr. 2020.

NINA, Carlos Homero Vieira. Escravidão, ontem e hoje: aspectos jurídicos e econômicos de uma atividade indelével sem fronteiras. Brasília, [s.n.], 2010.

ONG ESCRAVO NEM PENSAR. O que o trabalho infantil tem a ver com o trabalho escravo? Disponível em: <http://escravonempensar.org.br/livro/4-trabalho-infantil/\#3>. Acesso em: 02 abr. 2020.

ONG REDE PETECA. Disponível em: <https://www.chegadetrabalhoinfantil.org.br/>. Acesso em: 31 mar. 2020.

ONG REDE PETECA. Mapa do Trabalho Infantil. Disponível em: <https://www.chegadetrabalhoinfantil.org.br/mapa-do-trabalho-infantil/>. Acesso em: 31 mar. 2020.

ORGANIZAÇÃO DAS NAÇÕES UNIDAS. Agenda 8. Trabalho Decente e Desenvolvimento Econômico. Disponível em: <https://nacoesunidas.org/pos2015/ods8/>. Acesso em 02 abr. 2020.

ORGANIZAÇÃO INTERNACIONAL DO TRABALHO. 40 million in modern slavery and 152 million in child labour around the world. OIT. 19 set. 2017. Disponível em: <https://www.ilo.org/global/about-the-ilo/newsroom/news/WCMS_574717/lang-en/index.htm>. Acesso em 02 abr. 2020.

ORGANIZAÇÃO INTERNACIONAL DO TRABALHO. Convenção 138. Idade Mínima para Admissão. Disponível em: <https://www.ilo.org/brasilia/temas/trabalhoinfantil/WCMS_235872/lang--pt/index.htm>. Acesso em 02 abr. 2020.

ORGANIZAÇÃO INTERNACIONAL DO TRABALHO. Convenção 182. Convenção sobre Proibição das Piores Formas de Trabalho Infantil e Ação Imediata para sua Eliminação. Disponível em: <https://www.ilo.org/brasilia/convencoes/WCMS_236696/lang-pt/index.htm>. Acesso em 02 abr. 2020.

ORGANIZAÇÃO INTERNACIONAL DO TRABALHO. Recomendação 146. Sobre Idade Mínima para Admissão a Emprego. Disponível em: 
<https://www.ilo.org/brasilia/convencoes/WCMS_242723/lang--pt/index.htm>. Acesso em 02 abr. 2020.

ORGANIZAÇÃO INTERNACIONAL DO TRABALHO. Recomendação 190. Sobre Proibição das Piores Formas de Trabalho Infantil e Ação imediata para sua Eliminação. Disponível em: <https://www.ilo.org/brasilia/temas/trabalho-infantil/WCMS_242762/lang-pt/index.htm>. Acesso em 02 abr. 2020.

RIZZINI, Irene. O Século Perdido: raízes históricas das políticas públicas para a infância no Brasil. 3.ed. São Paulo: Cortez Editora, 2011.

SEN, Amartya. Desenvolvimento como Liberdade. Trad. Laura Teixeira Motta. Rev. Téc. Ricardo Doninelli Mendes. São Paulo: Companhia das Letras, 2010.

WALK FREE FOUNDATION. The Global Slavery Index. Disponível em: <https://www.globalslaveryindex.org/ >. Acesso em 1 abr. 2020. 